\title{
Fishing strategy diversification and fishers' ecological dependency
}

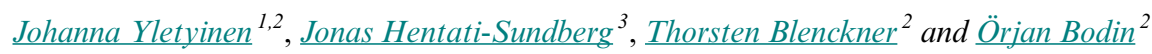

\begin{abstract}
Sustainable fisheries management plays a critical role in supporting healthy marine ecosystems and the livelihoods of millions of people. An emerging view on fisheries management emphasizes the need to manage fisheries as complex social-ecological systems. Yet, our understanding of the outcomes of fisheries management from a social-ecological perspective is limited in comparison to that provided by either the biophysical or the social perspective alone. In the Baltic Sea, management interventions focused on ecosystem recovery contributed to unintended changes from 1996 to 2009 in the fishing strategy diversity practiced by Swedish fishers. We evaluate how the changes in strategy diversification affected the capacity of Swedish fishers to adapt to future ecosystem changes. To do this, we constructed and analyzed social-ecological fisheries networks. Our analysis confirmed the previously reported development of a narrower combination of fishing strategies among large-scale fishers, parallel with a diversification in small-scale fishers' strategies. However, the results demonstrated that switching fishing strategies has, in fact, increased in magnitude, and the fishers were more equally distributed in different fishing strategies in 2009 than in 1996. Further, we detected a development toward lower ecological dependency between fishing strategies within the community, although the strategies remained connected through ecological interactions. In conclusion, our analysis of the social-ecological interdependencies suggests that the previously reported changes in the fishing strategy diversity increased the adaptability of the Swedish Baltic Sea fishers to changing ecological conditions. On the other hand, the changes may have made the Baltic Sea more vulnerable to poor management. This empirical study emphasizes the importance of a social-ecological approach on fisheries research and management. Our results show that appreciating the complexity and changing nature of fisher behavior is crucial when assessing fisheries management outcomes, and when designing policies that aim to maintain adaptability in the uncertain and dynamic fish industry.
\end{abstract}

Key Words: adaptability; Baltic Sea; fishing strategies; métiers; motifs; social-ecological systems; social-ecological networks

\section{INTRODUCTION}

Global environmental change and the unprecedented scale of human actions require adaptability and a social-ecological perspective in natural resource management (Folke 2016). Fisheries respond to stresses from both societal and ecological sources due to their nature as coupled human and natural systems (Perry et al. 2011). An emerging view of fisheries management emphasizes the need to manage fisheries as adaptive, highly connected, and interacting social-ecological systems (SES) (Pikitch et al. 2004, Mahon et al. 2008, Wilson 2016). Seen from the SES perspective, humans act not only as external factors that influence the ecological system, but they also adjust their behavior in response to ecological change and various social and economic constraints (Rochet and Trenkel 2003, Christensen and Raakjær 2006, Folke et al. 2010, Fulton et al. 2011, Boonstra and HentatiSundberg 2014). However, fisheries management design and outcomes are usually assessed based on ecosystem status or fish production; the dynamic aspects of human harvesting behavior are often overlooked in resource management and harvesting models (Salas and Gaertner 2004, Bieg and McCann 2017).

Fishers' ability to switch between target species enables fishers to create diverse income sources, and to divert fishing effort to other species when a targeted species is depleted (Hilborn et al. 2001, Kasperski and Holland 2013). The "fishing strategy" or métier concept has been developed to characterize this kind of fishers' harvesting behavior. A number of available fishing strategies allow fishers to adapt to the changes in the environment and society (e.g., weather, changes in fish prices, migration of fish stocks) by, for instance, changing their target species, gear used, number of days at sea, and fishing area (Christensen and Raakjær 2006, Pelletier and Ferraris 2011). Changes in fishing strategies may even affect management outcomes through unexpected resource user behavior (Salas and Gaertner 2004, Fulton et al. 2011). Recently, Cline et al. (2017) showed that fishers' participation across a number of fisheries, and their ability to opportunistically shift the composition of exploited species, may significantly buffer against unexpected ecosystem regime shifts and changing markets. Creating and maintaining flexibility in fishing opportunities may therefore increase resilience and adaptive capacity of a fishing community (Cline et al. 2017), whereas management that prevents overfishing through technical regulation can limit fishers' ability to adapt to ecosystem change (Kasperski and Holland 2013, Hentati-Sundberg and Hjelm 2014).

Through complex social-ecological linkages, the ability of fishers to switch fishing strategies thus affects the health of fish stocks, which, in turn, can affect the fishers' choice of harvesting strategy. We address the question of how changes in strategy switching and social-ecological connectivity affect fishers' ability to respond to ecosystem changes - i.e., their adaptability (Folke et al. 2010) in the Baltic Sea context.

The Baltic Sea is a north-European large, brackish water ecosystem with a mix of marine, freshwater, and anadromous species. The overall species richness and biodiversity of the Baltic fish community is low in comparison to similar-sized ecosystems elsewhere (Mackenzie et al. 2007). The sea is under multiple regional and global anthropogenic pressures, and has experienced 
abrupt ecosystem changes in the past (Österblom et al. 2007, Möllmann et al. 2009, Olsson et al. 2015, Yletyinen et al. 2016). Management plays a major role in the development of the Baltic Sea fisheries, especially as the abundance and habitats occupied by the Baltic Sea fish are expected to change in the future (Mackenzie et al. 2007, Niiranen et al. 2013, Blenckner et al. 2015).

Commercial fishing has a long tradition in Baltic Sea countries (see Feistel et al. [2008] and Zeller et al. [2011] for estimates of fisheries removals in the recent decades), and fishing is one of the anthropogenic drivers that has contributed to significant changes in the Baltic ecosystems (Österblom et al. 2007, Casini et al. 2008, Niiranen et al. 2013, Lade et al. 2015). Sweden has, along with Denmark and Poland, the largest commercial fisheries in the Baltic Sea (Waldo et al. 2010, ICES 2017). Swedish fisheries extend from small-scale coastal fisheries with nets, hooks, and traps to offshore large-scale fisheries that target cod and small pelagic species by using bottom and pelagic trawls (Boonstra and Hentati-Sundberg 2014). Swedish fisheries systems and policies sit under both regional and international fisheries agreements. When Sweden joined the European Union in 1995, Swedish fisheries policy and management became part of European fisheries regulation. Regulation of commercial offshore fisheries (beyond national waters) is an exclusive competence of the European Union, under the auspices of the Common Fisheries Policy, whereas fishing for most coastal species is regulated on the national levels. In addition, several aspects of fisheries policy for offshore waters have national legislation that complements the regulation and directives on the European level (Eggert and Tveterås 2007, Aps and Lassen 2010, ICES 2017, ICES Advisory Committee 2017). Swedish fisheries are subject to total allowable catches for each commercially important species, accompanied by other measures. In line with the general goal of the Common Fisheries Policy, in the previous one to two decades, Swedish fisheries policy has focused on reducing fishing effort. This has been done mainly through implementing access regulations, setting fleet reduction targets, and limiting flexibility between fisheries through various types of technical regulations (HentatiSundberg and Hjelm 2014, Hentati-Sundberg et al. 2015). For example, since the mid-2000s, a Swedish fisher has generally not been permitted to target both small pelagic species and cod (Hentati-Sundberg and Hjelm 2014).

During the years 1995-2009, Swedish fishers experienced interannual fluctuations in fish stock status and prices, and introduction of new types of management measures. For this study period, Hentati-Sundberg et al. (2015) detected a reduced diversification of fishing strategies among the Swedish large-scale fishers: individual fishers had started to practice a narrower combination of different types of fishing. The opposite trend was detected among small-scale fishers, who increasingly switched ${ }^{[1]}$ between different fishing strategies. In general, the trends indicated reduced social-ecological resilience in that it had become less common for fishers to practice a broad combination of different types of fishing strategies (Hentati-Sundberg et al. 2015). Potential drivers for the fishing strategy changes within the Swedish fishing community have been studied in relation to changes in fish stocks, fish prices, and regulations. The analyses suggested both direct and indirect effects between the drivers and strategy switching (Hentati-Sundberg et al. 2015). However, the results show that regulations played a significant role in shaping the system (Hentati-Sundberg and Hjelm 2014, Hentati-Sundberg et al. 2015). A thorough understanding of what drives and limits the harvesting decisions and behavior of individual fishers would require a broad analysis that included, for example, fishing investment (vessel, gear), community norms, individual expectations, individual preferences, and geography (Raakjær Nielsen 2003, Salas and Gaertner 2004, Christensen and Raakjær 2006).

This study investigates the ecological consequences of the previously recorded changes in the switching behavior of Swedish fishers. Given that the most commercially important fish stocks in the Baltic Sea have fluctuated substantially in the past decades in relation to both fishing and environmental variability (Ojaveer et al. 2010, Ojaveer 2017), it is relevant to question how well the restructured fishers' community can respond to future changes. Such a perspective-i.e., a combined social and ecological perspective - calls for integrated analyses of how the social and the ecological components interact, and how this interaction affects the social-ecological adaptability to future changes. We explore (1) how the changes in strategy diversification affected Swedish fishers' capacity to adapt to ecosystem changes, and (2) whether the restructuring of the fishing community altered the ecological dependency between fishing strategies, and hence the extent to which a shift in strategy changes the actual pressure on fish stocks at a more systemic ecosystem level. Network analysis has proved to be a valuable method of empirically disentangling how the structure of social-ecological systems can influence resource use (Bodin and Prell 2011). For this study, we constructed social-ecological networks (see an example in Fig. 1) for the years 1996 and 2009. We performed a network analysis to study how the changes in fishing strategy diversification formed potential changes in the social network structure (network compartmentalization), and interpreted the new structure in relation to fishers' ability to adapt to ecosystem changes. We then applied network motif analysis to examine the links between fishers and their target species (social-ecological connectivity) by studying whether the restructuring of the fishing strategies altered ecological dependency. The assessment of ecological dependency is based on either shared target species or fish species connected through trophic relationships.

\section{METHODS}

\section{Analysis of fishing strategies}

This analysis is based on a classification of fishing strategies in Swedish commercial fisheries, reported in Hentati-Sundberg et al. (2015) and Boonstra and Hentati-Sundberg (2014). The analysis relies on data reported in (mandatory) logbooks by individual fishers that covered the whole Swedish fleet in the Baltic Sea in the years between 1996 and 2009. A fishing strategy was defined as a combination of catch species, area, fishing gear, and season, and was classified based on multidimensional scaling and cluster analysis (Hentati-Sundberg et al. 2015). For example, one fishing strategy could be "cod fishing with nets," whereas another fishing strategy could be "trawl fishing for cod and flounder." In these types of analyses, there is always a trade-off between specificity and number of strategies (essentially each fishing trip is unique); we present a version with 13 strategies, which we consider a manageable number that maintains much of the 
essential variation in the original data. The fishing strategies ranged from very specialized (targeting single species with single gears) to more generalist (combining several gear types and target species within the same trips). Thus, fishers can theoretically be diverse by switching between a number of individually specialized fishing strategies, although that is seldom the case because specialization (i.e., focusing on one or another fishing strategy) is usually linked to specialized technologies, and is increasingly legally limited through licensing systems for individual species. Between 1996 and 2009, species-specific fishing licenses for cod, salmon, eel, and small pelagic species were introduced, which drastically reduced the possibility for individuals to switch between the strategies associated with those species.

Fig. 1. The social-ecological network of the Baltic Sea Swedish fishers demonstrates the complexity of fisheries interactions. (A) Social network, in which nodes are fishing strategies and links represent switching; (B) intermediate social-ecological network, in which nodes are fishing strategies and fishes, and links represent fishing; (C) ecological network, in which nodes are the main target fish species of Swedish fishing strategies, and links are predator-prey relationships. FS: fishing strategy, CO: cod, HE: herring, SP: sprat; SA: salmon, FL: flounder, PL: plaice, NP: northern pike, PP: pikeperch, PE: perch, TU: turbot, EE: eel, WH: whitefish, TR: sea trout.

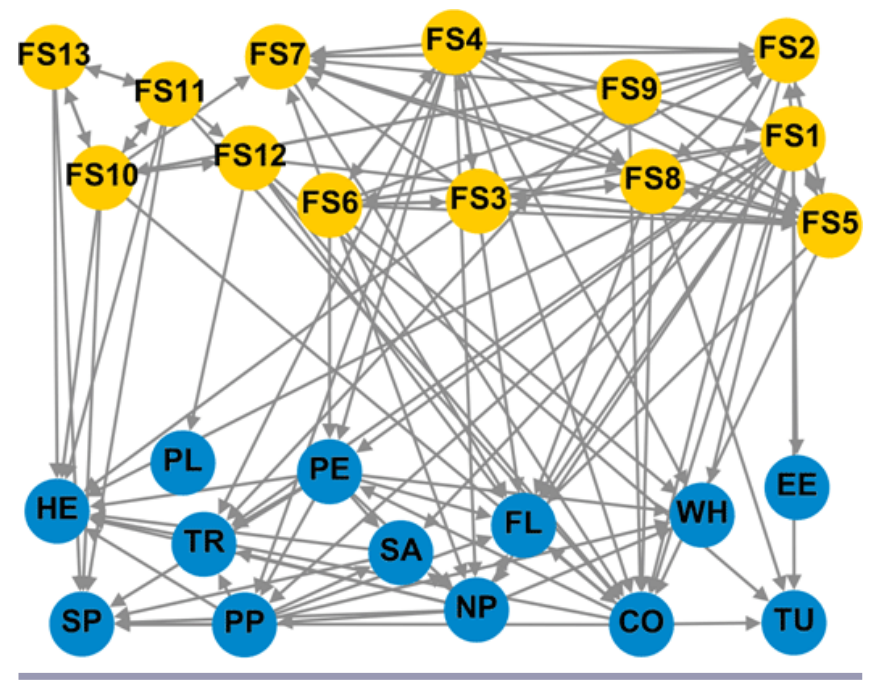

In our analysis, we defined for each fisher their primary fishing strategy as the strategy they performed the most times within a year (measured as number of days for large-scale fishers or number of months for small-scale fishers [under $10 \mathrm{~m}$ ]). A temporary fishing strategy was any other fishing strategy performed by the same fisher within a year.

Network compartmentalization and social-ecological connectivity We examined two network properties to study the structure and potential changes in the Swedish fishery system for the years 1996 to 2009: compartmentalization and social-ecological motifs. Those two years were chosen because we know that significant changes in fisheries management (new types of technical regulations) had taken place, and that significant restructuring had already been reported for this period; e.g., in terms of increased specialization of fishing strategies.
A common property in many networks is compartment (also called community) structure (Girvan and Newman 2002). Network compartments are densely connected subgroups of actors (network nodes) that interact more within their compartment (higher connectivity) and have sparser interactions with the actors of different compartments (lower connectivity) (e.g., Newman 2006). Identifying compartments is of interest in network analysis because compartmentalization significantly influences system dynamics, and so detecting and identifying compartments can help to understand and exploit networks more effectively (Girvan and Newman 2002). For example, compartmentalization can affect spread of perturbation (May 1972, May et al. 2008, Stouffer and Bascompte 2011), indicate undesired fragmentation (Bodin and Norberg 2006), prevent stabilizing feedbacks (May et al. 2008), and lead to trade-offs between local and system-wide risks. Compartmentalization can also indicate lower system redundancy, since the formation of compartments affects which system components and pathways can substitute for one another (fewer parallel pathways within the entire network) (May et al. 2008). As illustrated by these examples, whether the effect of compartmentalization is desired or undesired is context-dependent and should be interpreted in relation to what the network represents. In our social networks, detecting compartments would point out the presence of concentrated groups of fishing strategies; i.e., compartments of fishing strategies in which switching occurs more within compartment than with outside-compartment fishing strategies. In addition to the compartmentalization as a topological network feature, our network of the Swedish fishers includes link weights (the proportion of fishers switching from one strategy to another) and node attributes (number of fishers per main strategy; i.e., how fishers are distributed within the fishing strategies).

The social-ecological motifs approach provides a framework for studying interdependencies between resource users (social actors) and ecological resources (Bodin and Tengö 2012). The approach is based on the assumption that an SES can be modeled as a social-ecological network (Bodin and Tengö 2012), and that network motifs can be used to uncover the building blocks of complex networks (Milo et al. 2002). Motifs (Fig. 2) are patterns of interconnections (microlevel substructures) that appear in networks at numbers significantly higher or lower than in suitably randomized networks (Milo et al. 2002). By defining a set of motifs that represent important characteristics of an SES, and examining how frequently the motifs of interest appear in the empirical social-ecological networks, we can unpack and define the ways social actors and ecosystems are connected, and potentially link (using relevant theories on various forms of social-ecological interactions) the detected characters to social and ecological outcomes (Bodin and Tengö 2012). We used the social-ecological motif approach to evaluate the ecological connectivity of the Baltic Sea fishing strategies; namely, to what extent the fishing strategies are connected (ecologically dependent) based on shared species.

\section{Analyses}

Step 1: Construct a social-ecological network representing the fishing strategies and the target species

The starting point for our analysis was to construct a network representation of the different fishing strategies and the target 
fish species. We used empirical data on fishing strategies from Baltic Sea Swedish fishers, the classification of which is described in detail elsewhere (Boonstra and Hentati-Sundberg 2014, Hentati-Sundberg et al. 2015). The strategies, along with the main target species and gears, are listed in Table 1.

Fig. 2. Left: a social-ecological motif in which grey social nodes represent fishing strategies, and white ecological nodes represent target fish species. A link between social nodes represents fishers switching between fishing strategies, and a link between ecological nodes represents predator-prey relationships. A link from social node to ecological node represents fishing. Motif links are unweighted and undirected. The set of six motifs on the right side shows the socialecological motifs that are included in this study.
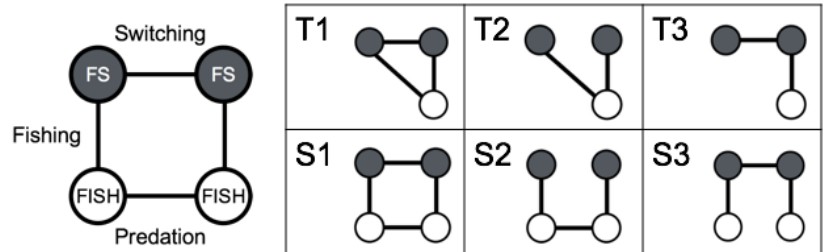

\section{Fishers network construction}

In the fishing strategies network, a node is a specific fishing strategy. The size of the node is determined by the number of fishers using the fishing strategy as a primary strategy. A link represents switching between the strategies. The weight of the link indicates the percentage of fishers that combined their primary strategy with another temporary fishing strategy. Because the data used to create these links describe switching that has taken place, we cannot know for sure whether the fishers actually would have capacity to switch even to other strategies. (Similarly, in ecological network research, a food web is often constructed based on stomach contents data and other observed predation-prey interactions, yet wider prey switching could be possible although not recorded.) We assume that because we do not see any switching to other strategies, it could be because the switchers are for some reason unwilling to switch, or are unable to do so.

A link was added between a primary fishing strategy and a temporary fishing strategy if $5 \%$ or more of the primary fishing strategy fishers switched to the temporary strategy within a year. The direction of the link is from the primary to the temporary fishing strategy. The number of nodes is 13 for both networks (although in 1996, the fishing strategy labeled "FS11" was not practiced as a primary fishing strategy by any fisher). Table 2 includes network measures that describe the average switching between fishing strategies. Graph density indicates the proportion of links in a network that are actually present in relation to the maximum number of possible links in the network. In practice, it describes the amount of realized fishing strategy switching compared to all possible switching opportunities. The average degree is the average sum of the links per node (i.e., does not take into consideration link weight or link direction), and the weighted degree is the average of link weights per node. Since networks for 1996 and 2009 have the same number of nodes, density and degree measures were comparable.
Table 1. The 13 fishing strategies that are included in the study. Fishing strategies FS10-FS13 are large-scale fishing strategies. Modified from (Boonstra and Hentati-Sundberg 2014).

\begin{tabular}{|c|c|c|c|}
\hline ID & Primary target species & $\begin{array}{l}\text { Gear and mesh } \\
\text { size (quartiles) }\end{array}$ & $\begin{array}{c}\text { Vessel } \\
\text { length }(\mathrm{m})\end{array}$ \\
\hline FS1 & $\begin{array}{l}\text { European eel (Anguilla anguilla), } \\
\text { northern pike (Esox lucius), perch } \\
\text { (Perca fluviatilis), European flounder } \\
\text { (Platichthys flesus), cod (Gadus } \\
\text { morhua), whitefish (Coregonus spp.), } \\
\text { herring (Clupea harengus) }\end{array}$ & $\begin{array}{l}\text { pots and traps, } \\
19-44 \mathrm{~mm}\end{array}$ & 6.7 \\
\hline FS2 & cod, European flounder & $\begin{array}{l}\text { gillnets, } 110-120 \\
\mathrm{~mm}\end{array}$ & 9.7 \\
\hline FS3 & herring & $\begin{array}{l}\text { gillnets, } 36-40 \\
\mathrm{~mm}\end{array}$ & 7.7 \\
\hline FS4 & $\begin{array}{l}\text { northern pike, whitefish spp., perch, } \\
\text { pikeperch (Sander lucioperca), sea } \\
\text { trout (Salmo trutta), European } \\
\text { flounder }\end{array}$ & $\begin{array}{l}\text { gillnets, } 92-100 \\
\mathrm{~mm}\end{array}$ & 7.7 \\
\hline FS5 & cod, European flounder & $\begin{array}{l}\text { gillnets, } \\
\text { bottom trawls, } \\
120-130 \mathrm{~mm}\end{array}$ & 10.0 \\
\hline FS6 & $\begin{array}{l}\text { perch, northern pike, whitefish spp., } \\
\text { pikeperch, European flounder }\end{array}$ & $\begin{array}{l}\text { gillnets, } 70-96 \\
\mathrm{~mm}\end{array}$ & 7.1 \\
\hline FS7 & $\operatorname{cod}$ & lines & 9.6 \\
\hline FS8 & $\begin{array}{l}\text { turbot (Scopthhalmus maximus), cod, } \\
\text { European flounder }\end{array}$ & $\begin{array}{l}\text { gillnets, } 220-240 \\
\mathrm{~mm}\end{array}$ & 9.4 \\
\hline FS9 & salmon (Salmo salar), sea trout & driftnets, $160 \mathrm{~mm}$ & 12.0 \\
\hline FS10 & herring, cod, sprat (Sprattus sprattus) & $\begin{array}{l}\text { bottom trawl, } \\
\text { midwater trawl, } 32 \\
\text { mm }\end{array}$ & 24.0 \\
\hline FS11 & herring, cod, sprat & $\begin{array}{l}\text { bottom trawl, } \\
\text { midwater trawl, } \\
16-20 \mathrm{~mm}\end{array}$ & 20.0 \\
\hline FS12 & $\begin{array}{l}\text { cod, European plaice (Pleuronectas } \\
\text { platessa), European flounder, turbot }\end{array}$ & $\begin{array}{l}\text { bottom trawl, } \\
100-105 \mathrm{~mm}\end{array}$ & 22.0 \\
\hline FS13 & sprat, herring & $\begin{array}{l}\text { midwater trawl, } \\
16-22 \mathrm{~mm}\end{array}$ & 39.0 \\
\hline
\end{tabular}

Table 2. Network measures for fishing strategies and compartment membership results for fishing strategies. Only $40 \%$ and $35 \%$ of all the potential links in the networks are present in the 1996 and 2009 networks, respectively. The numbers for fishing strategy (FS) ID follow the numbering of fishing strategies in Table 1 and Fig. 3. The compartment membership (C) represents the compartment to which each fishing strategy belongs; e.g. FS1, FS, FS3, and FS6 all belong to the same compartment, which is indicated by membership number 1 in Table 1 and yellow in the Fig. 3.

\begin{tabular}{|c|c|c|c|c|c|c|c|c|c|c|c|c|c|c|}
\hline \multirow{2}{*}{$\begin{array}{c}\text { Network } \\
1996\end{array}$} & \multicolumn{4}{|c|}{$\begin{array}{l}\text { Number of } \\
\text { compartments }\end{array}$} & \multicolumn{3}{|c|}{$\begin{array}{c}\text { Number of } \\
\text { links }\end{array}$} & \multicolumn{3}{|c|}{ Graph density } & \multicolumn{4}{|c|}{$\begin{array}{c}\text { Average degree/ } \\
\text { average } \\
\text { weighted } \\
\text { degree }\end{array}$} \\
\hline & \multicolumn{4}{|c|}{3} & \multicolumn{2}{|c|}{63} & & \multicolumn{3}{|c|}{0.404} & \multicolumn{4}{|c|}{$9.70 / 97.69$} \\
\hline 2009 & \multicolumn{4}{|c|}{2} & \multicolumn{3}{|c|}{54} & \multicolumn{3}{|c|}{0.346} & \multicolumn{4}{|c|}{$8.31 / 127.77$} \\
\hline \multicolumn{15}{|c|}{ Compartment membership: } \\
\hline \multirow[t]{2}{*}{1996} & FS & 1 & 2 & 3 & 4 & 5 & 6 & 7 & 8 & 9 & 10 & 11 & 12 & 13 \\
\hline & $\mathrm{C}$ & 1 & 2 & 1 & 1 & 2 & 1 & 2 & 2 & 2 & 3 & 3 & 3 & 3 \\
\hline \multirow[t]{2}{*}{2009} & FS & 1 & 2 & 3 & 4 & 5 & 6 & 7 & 8 & 9 & 10 & 11 & 12 & 13 \\
\hline & $\mathrm{C}$ & 1 & 1 & 1 & 1 & 2 & 2 & 2 & 2 & 1 & 1 & 1 & 1 & 1 \\
\hline
\end{tabular}




\section{Ecological network construction}

The links between fish species are predator-prey links (Yletyinen et al. 2016, Jens Olsson, Swedish University of Agricultural Sciences, personal communication). Only the main target species in Table 1 were included in the social-ecological network model since we were mostly interested in the effects that changing fishing pressure can have on the fishery. Hence, potential effects on other species were not accounted for, nor were any indirect ecological effects (e.g., when the abundance of a prey species affects the abundance of a top predator, which would consequently affect the top predator's preying on the primary predators of the prey species in an intermediate trophic level).

\section{Social-ecological systems network construction}

The SES network included the fishing strategies network and their target species (Table 1). We calculated the average catch quantity per fishing event ("trip") by dividing the total catch per year by the number of trips. Using these catch data, we calculated catch per "average fisher" by dividing the amount of catch per fishing strategy by the number of fishers practicing the fishing strategy. A link was added from a fishing strategy to a target fish if the average catch for a species per trip exceeded $2 \%$ of the average total catch per trip for that particular fishing strategy. The links between social nodes represent switching, the links between social and ecological nodes represent the relationship between the strategies and the target species, and the links between ecological nodes represent predator/prey relationships (Fig. 1).

The data used to construct the social-ecological networks can be found in Tables A1.1, A1.2, A2.1, A2.2, and A5 in Appendix 1.

\section{Step 2: Social-ecological network analysis Compartment detection}

To examine if compartments were present in the networks, we used a compartment detection algorithm for directed and weighted social (fishing strategies) networks. The GirvanNewman algorithm for community detection calculates betweenness centrality indices to detect community boundaries (Girvan and Newman 2002, Newman and Girvan 2004) with the following principles:

1. Calculate the betweenness (shortest path betweenness; i.e., links connecting many pairs of nodes) for all links in the network.

2. Remove the link with the highest betweenness.

3. Recalculate betweenness for all links affected by the removal.

4. Repeat from Step 2 until no links remain.

By removing the in-between links, nodes that are joined together in densely linked groups are separated from each other, and the underlying compartment structure of the network is revealed (Girvan and Newman 2002). We used igraph package in the $R$ environment to run the Girvan-Newman algorithm (Csárdi and Nepusz 2006, R Core Team 2013). Threshold sensitivity analysis for motif analysis and network construction is presented in Appendix 1, Table A3.

\section{Social-ecological motifs analysis}

For the motif analysis, we treated the links as undirected and unweighted (following Cinner and Bodin 2010). We limited the analysis to six motif types (Fig. 3). The motif analysis was performed in R environment ( $\mathrm{R}$ Core Team 2013) as follows:

Fig. 3. Fishing strategies compartments. The size of the node is in relation to the number of fishers practicing the strategy as their primary fishing strategy. The link weight indicates the number of fishers switching between the styles. Note, however, that although the direction of the link is not presented in the graph, the flow between two fishing strategies is not necessarily equal from both directions. In this visualization, for instance, if $8 \%$ of fishers with FS1 can switch to FS6, and 44\% of FS6 fishers can switch to FS1, the size of the link is in relation to $44 \%$ (two overlapping arrows; the weaker link is "hidden below" the stronger link).
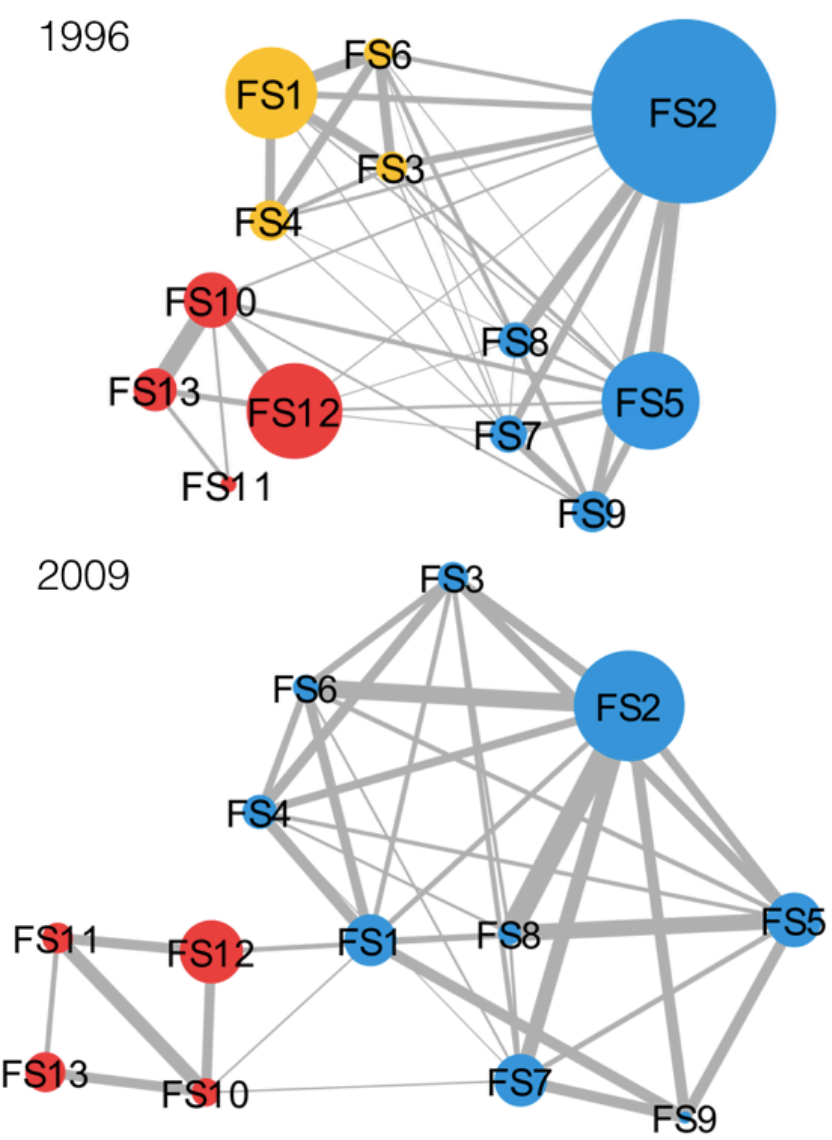

1. Quantify the frequencies of all six motifs from the full-scale social-ecological network, including all possible combinations of social actors and ecological resources (social and ecological nodes).

2. Compare the motif frequencies in the empirical network to the mean value and the standard deviation drawn from 1000 random networks with the same number of social, 
ecological, and social-ecological links. In this comparison, the set of random networks provides a null model.

3. The extent to which the distribution of motifs deviates from the null model informs whether any of the motifs occur more or less than could be expected by random. Statistical significance is based on the percentage of random networks that include more/less of the specific motif than the empirical network.

Hence, motif overrepresentation means that a motif occurs more in an empirical network than in the assembly of random networks, and motif underrepresentation means that the motif occurs less frequently in an empirical network than in the assembly of random networks. The threshold sensitivity analysis for motif analysis and network construction is presented in Appendix 1, Table A3.

The SES motif results in Table 3 present two critical numbers for each motif: empirical count and T-ratio. The empirical count describes how common the motif is in the empirical network, and the T-ratio describes if the count differs significantly from what could be expected (i.e., by how many standard deviations the motif counts from the empirical network differ from the means drawn from the random networks). This distinction is important to make because, for example, T3 in 1996 was more common than T1 according to the empirical count. Compared to the baseline of random networks, however, there was a significant underrepresentation of T3 motifs and significant overrepresentation of T1. In this study, we discuss only the motif over/ underrepresentation based on T-ratios (not the empirical counts), but to improve readability, we use the words common/uncommon to describe their empirical count in the Results and Discussion sections.

Table 3. Motif analysis for 1996 and 2009 social-ecological networks. Motifs were compared to 1000 random networks with the same number of links as empirical networks. Statistical significance was based on the actual percentage of random networks that had more/less of the specific motif versus the empirical network. * the fraction is $<0.05$; ** the fraction is $<$ 0.01 . Plus and minus signs signal whether the motif is overrepresented $(+)$ or underrepresented $(-)$ in frequency.

\begin{tabular}{|c|c|c|c|c|c|c|c|c|}
\hline \multirow{2}{*}{$\begin{array}{c}\text { Motif } \\
\mathrm{T} 1\end{array}$} & \multicolumn{2}{|c|}{$\begin{array}{c}\text { Empirical } \\
\text { count }\end{array}$} & \multicolumn{2}{|c|}{$\begin{array}{c}\text { Random } \\
\text { count (mean) }\end{array}$} & \multicolumn{2}{|c|}{$\begin{array}{l}\text { Standard } \\
\text { deviation }\end{array}$} & \multicolumn{2}{|c|}{ T-ratio } \\
\hline & 15 & 3 & 7.9 & 1.9 & 2.5 & 1.3 & $\begin{array}{l}2.9^{* *} \\
+\end{array}$ & 0.86 \\
\hline $\mathrm{T} 2$ & 3 & 1 & 5.3 & 2.3 & 2.0 & 1.3 & 1.1 & 0.9 \\
\hline T3 & 102 & 50 & 118.4 & 61.5 & 6.3 & 4.7 & $\begin{array}{c}2.6^{* *} \\
-\end{array}$ & $\begin{array}{c}2.5^{*} \\
-\end{array}$ \\
\hline S1 & 30 & 3 & 30.1 & 9.7 & 7.0 & 3.6 & 0.0 & $\begin{array}{c}1.9^{*} \\
-\end{array}$ \\
\hline S2 & 38 & 18 & 20.5 & 9.7 & 5.2 & 3.6 & $\begin{array}{c}3.4^{* *} \\
+\end{array}$ & $\begin{array}{c}2.3^{*} \\
+\end{array}$ \\
\hline S3 & 25 & 6 & 38.4 & 11.0 & 7.8 & 3.8 & $\begin{array}{c}1.7^{*} \\
- \\
\end{array}$ & 1.3 \\
\hline
\end{tabular}

The selection of the motifs (Fig. 2) was based on the assumption that to adapt to fish stock fluctuations, fishers should ideally have the ability to switch to a fishing strategy that targets other species.
Further, from the ecological perspective, the species should not be directly ecologically connected because the fishing pressure on either of the interacting species will affect the other through predation. The triad motifs (three nodes) model three different dependencies between two fishing strategies and a target fish species. In T1, both fishing strategies targeted the same species; thus, a switch between fishing strategies did not entail change from one target species to another. This implies an inflexible characteristic of the social-ecological network because the resource user is harvesting the same species despite the switching. In T2, the fishing strategies that target the same species were not linked to each other; i.e., switching did not occur between the fishers of the same species. The T2 motif represented competition on the shared resource between two fishing strategies that are used by two distinct sets of fishers. We do not suggest this motif is either beneficial or detrimental; the motif reflects adaptive harvesting, but the competition itself might be harmful. In T3, a fish species was targeted by only one of the two interconnected fishing strategies, and fishers thus had the ability to switch to/ from fishing the targeted species. We considered this motif conducive to adaptability. The square (four nodes) motifs consisted of dependencies between two fishing strategies and two target fish species. In the S1 and S3 motifs, the two fishing strategies both target a species of their own. Switching between the fishing strategies enables fishers to target different fish species. Both of these motifs thus represented adaptability, but we assert that S3 (where the fish species are ecologically independent) is able to provide more social-ecological flexibility since moving between the strategies would imply targeting independent fish species. In S1 and S2, the target fish species were directly connected through predation, and were thus affected by fishing through two pathways: direct fishing effort and indirectly through fishing-induced predator/prey abundance. In S2, the fish species were connected through predation, but the fishers in fishing strategies targeting them did not switch between the strategies. Thus, each of the two fishing strategies was affected by each other's fishing through predator-prey interactions among their target species. Similar as for T2, we do not suggest this as being beneficial (or not) from an adaptation point of view.

We acknowledge that this is a simplification at the two species' level, ignoring the complex and often indirect ways through which fishing affects fish abundance and food web dynamics (Pauly and Palomares 2005, Worm et al. 2006, Essington et al. 2015). Nonetheless, our study enabled a novel analysis of socialecological interdependencies, albeit that the coarse-grain nature of the analysis calls for caution in (over)interpreting the results.

\section{RESULTS}

\section{Social compartmentalization}

We detected two structural changes in the compartmentalization networks. The first structural change was in division of networks in the compartments, as the number of compartments decreased from three in 1996 to two in 2009 (Fig. 3, Table 2). In the 1996 network, each of the three compartments consisted of four to five fishing strategies. The 2009 network consisted of one large compartment of nine nodes and one small compartment of four nodes. The blue compartment indicated mainly the use of passive fishing techniques targeting cod, flounder, and salmon, with turbot and sea trout as additional, less important target species. 
The yellow compartment indicated the nearshore fishing with nets and traps targeting European eel, freshwater species (such as northern pike), and herring. The red compartment indicated the trawl fishing targeting cod, herring, and sprat. In 2009, the archipelago (yellow) compartment had disappeared and the fishers from that compartment became part of the larger coastal (blue) compartment. The connectivity between the compartments was sparser in 2009 , measured by the number of connections between them; i.e., seven links between blue and red compartment in 1996, three in 2009.

The second structural change detected by our analysis includes link weights and node sizes. The change in the latter indicated that the 2009 network was in general more uniform in the distribution of fishers among fishing strategies. This implies that the diversity among the fishers had increased since 1996 (c.f. the Shannon diversity index - the more uniform the distribution of individuals into a fixed set of categories, the more diversified the population). In regard to the change in link weights, there were more strong links within-compartment in 2009 than in 1996, and links between compartments were overall weaker in 2009 than in 1996. In addition, the average weighted degree (127.8) indicated a higher rate of switching among the fishers in 2009 than in 1996 (97.7), although the number of realized switching opportunities (graph density when a link is counted as 1 regardless of weight as long as it exceeds 0.05 ) was lower; i.e., the average degree was 8.3 in 2009 versus 9.7 in 1996 (Table 2).

\section{Social-ecological coupling}

The results for social-ecological coupling (Table 3 ) show that in 1996, the T1 and S2 motifs were common, and T3 and S3 were underrepresented. In other words, the network was characterized by fishers that were able to switch to another strategy (note that the link may be one-way; i.e. both fishers do not necessarily switch to each other's fishing strategy), but both of the strategies harvested the same species (T1 overrepresented, T3 underrepresented). This phenomenon is further demonstrated by the underrepresented motifs T3 and S3, and motifs S1 and T2 whose representation did not differ from what could be expected. These motifs represent fishing strategies that do not harvest the same species (T3, S1, S3), or where switching is not included (T2). Of the motifs in which both fishing strategies harvested separate species, the motif S2 was most significantly overrepresented in the 1996 network. S2 shows that two fishing strategies harvest two species in a direct predator-prey relationship (S2). Importantly, motif $\mathrm{S} 2$ is more common than motifs $\mathrm{T} 2, \mathrm{~S} 1$, or $\mathrm{S} 3$, indicating a lack of switching between fishers harvesting different species.

Comparing 2009 results to 1996, we detected changes in motif commonness (Table 3). Motif T1 is no longer overrepresented, while motif $\mathrm{S} 3$ is no longer underrepresented. This indicates a release from the 1996 pattern of targeting the same species despite switching a strategy. We also detected that motif S2 had become slightly less common, but nevertheless remains overrepresented, especially in relation to T3, S1, and S3. As a result, still in 2009, the fishing strategies that were not connected by switching are connected through ecological interactions (S2), although less commonly than in 1996. Decrease in T1, T3, S1, and S3, which all include a link between the social nodes, likely reflects the earlier noted community-level change to fewer switching opportunities.
We selected $2 \%$ as the cutoff for links between a fishing strategy and a fish species to deliberately treat weak links the same as stronger links. The rationale is that we consider even weak links to be useful from the adaptation point of view; i.e., the ability of fishers to shift fishing practices, even though the absolute fishing pressure between any two strategies can often be very different. However, to examine how much this cutoff value influenced our results, we undertook the same analysis for constructed socialecological networks where we changed the cutoff to $5 \%$ and $10 \%$ (Appendix, Table A4). These adjustments slightly changed some of the details of our results, although this sensitivity analysis demonstrated that our results remained broadly the same (changes in T1, S2) across this range of cutoff values.

Lastly, we complemented the motif analysis with a simple examination of weighted social-ecological links by drawing a graph of this part of the network (Appendix 1, Fig. A1 and Table A6). We did not detect clear system-wide changes in the distribution pattern of link weights connecting fishing strategies to fish species.

\section{DISCUSSION}

Theoretical and empirical research generally supports the view that a diversity of harvesting strategies provides options for responding to change and disturbance, although generalized understanding of how and where diversity builds resilience remains incomplete (Stirling 2007, Biggs et al. 2015). Our findings provide empirical evidence for the theoretical concept that diversity does not only refer to variety but includes distinct aspects: the number of categories into which system elements are apportioned (variety), how many of each type of element (balance), and how different the elements are from each other (disparity) (Stirling 2007). In our study, investigating changes in switching strategies included change to fewer compartments (variety). However, we also included examination of how much switching occurs within compartments and how the fishers are distributed among different primary fishing strategies (balance, disparity). The results show that although reduced diversity was detected on a system-level (fewer network compartments with fewer links between compartments), the diversity of switching increased in that individual fishers switched strategies more within their compartments and were more equally distributed to different fishing strategies.

The compartmentalization analysis showed an increasing specialization within large-scale fisheries, in agreement with Hentati-Sundberg et al. (2015). Adding to the previous knowledge, we found that fishers were switching more between the strategies within the large-scale fishing strategy (FS10-FS13) compartment in 2009 than in 1996, and the numbers of fishers per large-scale fishing strategy became more uniform. Changes in the large-scale fishing strategy compartment may be affected by the fact that FS11 was not used as a primary fishing strategy in 1996. For the small-scale fishing strategies (FS1-FS9), the link weights as well as compartmentalization showed a diversification: despite the small decrease in the number of switching, the number of fishers moving between different fishing strategies had increased. The number of fishers in each fishing strategy showed that both small-scale and large-scale fishers became more equally distributed across different primary fishing strategies. Switching 
within compartments can arise both as a result of a deliberate strategy to diversify (apply many different tactics over time), or as a result of being excluded from the most profitable opportunities; i.e. forced specialization (Ellis 2008).

Intriguingly, the three compartments we found in the 1996 network corresponded to what has previously been described as three fishing styles in the Baltic Sea fisheries. Categorization of fishing styles took into account fishers' mentality, drivers, and motivations (Boonstra and Hentati-Sundberg 2014). A group of fishers previously described as "entrepreneurial"-i.e., highly profit-driven and adaptable to ecological and economic changes coincided with the red compartment (Fig. 3). The yellow compartment consists of the "archipelago fishers" who were defined by their combination of several fishing tactics depending on fish abundance and season. The blue compartment is the large Baltic Sea Swedish coastal segment, somewhat intermediate between the archipelago fishers and the trawl fishers, which is partly profit-driven but also partly traditional in the use of fishing practices. The merging of the archipelago with the larger coastal compartment in 2009 likely occurred because of the general decline in number of fishers in that group, in combination with the forced diversification driven by a decline in profitable opportunities for archipelago fishers (Hentati-Sundberg et al. 2015). Identifying which SES component plays an important role for adaptability can guide management toward more sustainable harvesting while sustaining a large part of the Swedish fishing community. Hence, it is important to point out here that the largescale Swedish fishers were comparably more profitable in 2009 than in 1996 (Hentati-Sundberg et al. 2015), whereas small-scale fishers may have seen their profits decline over the studied time period. Thus, the likelihood that this potential increase in adaptability by small-scale fishers will remain over time is probably limited, since profits might drive small-scale fishers out of the business. Small-scale fishers could constitute an important asset for the future of more adaptive fishing in the Baltic Sea fisheries; e.g., through being in possession of local ecological knowledge (Crona 2006, Björkvik, Boonstra, Hentati-Sundberg et al. unpublished manuscript).

The social-ecological connectivity analysis indicated development toward lower ecological dependency among fishing strategies. For the first study period, the fishers lacked capacity (motif T1) (or will) for releasing fishing pressure on an overfished species to target some healthier stock, but this pattern was no longer detectable in 2009. Further, from an ecological perspective, a fishing strategy can affect pressure on a fish species by harvesting its predator/prey species. An indirect ecological dependency is thus formed if fishing strategies are connected through direct ecological interactions (predation) between target species. Our analysis showed such indirect ecological dependency to be common among the Swedish Baltic Sea fishers, albeit a little less common in 2009. Consequently, the results suggested that the ecological dependency of the fishers' community as a whole was reduced in that a switch in strategy increasingly changed the actual pressure on fish stocks, but the dependency through ecological interactions remained. Our ecological network included only a subset of the Baltic Sea fish species, and we are thus limited in interpreting our results in a wider ecological community context. Future studies should include a more detailed food web analysis in relation to the fishing strategies. In addition, fisheries connectivity analysis based on fishing strategy switching could be used to anticipate redistribution of fishing effort during perturbation of specific fish stocks (Fuller et al. 2017).

It is important to note that this study focused on examining a previously recorded fishing community restructuring by evaluating how the changes among social actors affected the entire social-ecological network, with comparison between two years. One may argue that the results could have been different if we had evaluated the situation only five years after 1996, for example. For interested readers, we recommend viewing the longitudinal analysis of the fishing strategy changes between 1996 and 2009 for small-scale and long-scale fishers presented in HentatiSundberg et al. (2015). It is always challenging to estimate, for example, how many years it takes for management efforts to fully come into effect, or to which time period the health of a fish stock should be compared. Further, our social network is based on recorded switching data, and changes in underlying drivers for the switching decisions could lead to the emergence of new switching links. Indeed, fisheries are complex social-ecological systems that continuously evolve. The key take-home message that we have empirically demonstrated here is the importance of evaluating the effects that the management that is focusing on ecosystem aspects may have on the resource users, as well as the consequent social-ecological dynamics.

Although ideally, the resilience of the entire social-ecological system should be maintained, resource management solutions rarely can benefit all (e.g., ecological, economic, cultural) components of the system. Yet, the management of specific components can affect dynamics and structures of the entire system (Robards and Greenberg 2007). Our study emphasizes the importance of a social-ecological approach on fisheries management by disentangling changes in a fishers' social component driven by management that focuses on ecosystem recovery, and then examining the effects that the social restructuring can have on the ecosystem. Our findings clarify social consequences of the Baltic Sea ecosystem-focused management. In conclusion, the Swedish fishers' community had become more capable of responding to ecological changes, thereby making the Baltic Sea more receptive to adaptive management. On the other hand, the Baltic Sea had become vulnerable to poor management as the increased adaptability of the Swedish fishers was provided mostly by the least profitable fishers, and the social restructuring could have allowed higher pressure and potential overfishing of several species of high demand (switching increasingly allowed change of target species). Social-ecological systems are never static, and the observed trends among Swedish fishers may also result from technological development or socio-economic changes in the society; i.e., the changes are not solely the responsibility of fisheries managers.

Through a complementary use of network approaches, our study provides new knowledge on harvesting strategy aspects that affect resource users' adaptability to changing ecological conditions. Our study clearly demonstrated that examining how fishers operate, and how the social and ecological systems influence each other, contributes to increased understanding about how the entire social-ecological fishery system works. Further, our findings highlight the conceptual importance of human behavior in relation to fisheries management (Hilborn et al. 2004, Salas 
and Gaertner 2004, Fulton et al. 2011). Similar to what has been argued in the context of ecosystem dynamics (Travis et al. 2014), scientists need to pay more attention to the behavior and interactions of resource users. Fisheries management needs to account for heterogeneous human responses in order to maintain adaptability, and to ensure sustainable and resilient development in an unpredictable future (Folke et al. 2016).

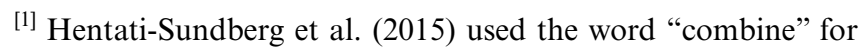
fishers' sequential combination of their main strategy with other strategies within a year. We use the word "switch" for this process.

Responses to this article can be read online at: http://www.ecologyandsociety.org/issues/responses. php/10211

\section{Acknowledgments:}

We thank Jens Olsson for his contribution to coastal fishes' predator-prey interactions, and Wiebren Boonstra, Jason Tylianakis, Roger Pech, and Audrey Lustig for valuable comments on the earlier versions of the manuscript. This paper is a deliverable of the Nordic Centre for Research on Marine Ecosystems and Resources under Climate Change (NorMER), which is funded by the Norden Top-level Research Initiative sub-programme "Effect Studies and Adaptation to Climate Change." Further, this work was financed by the BONUS INSPIRE project supported by the Joint Baltic Sea Research and Development Programme BONUS (Art 185), funded jointly by the EU and the Swedish Research Council Formas (Sweden). We also acknowledge funding by MISTRA through a core grant to Stockholm Resilience Centre. Ö. Bodin also acknowledges funding by the Swedish Research Council and Formas.

\section{LITERATURE CITED}

Aps, R., and H. Lassen. 2010. Recovery of depleted Baltic Sea fish stocks: a review. ICES Journal of Marine Science 67 (9):1856-1860. http://dx.doi.org/10.1093/icesjms/fsq118

Bieg, C., and K. S. McCann. 2017. The dynamical implications of human behaviour on a social-ecological harvesting model. Theoretical Ecology 10(3):341-354. http://dx.doi.org/10.1007/ $\underline{\text { s12080-017-0334-3 }}$

Biggs, R., M. Schlüter, and M. L. Schoon, editors. 2015. Principles for building resilience. Cambridge University Press, Cambridge, UK.

Blenckner, T., H. Österblom, P. Larsson, A. Andersson, and R. Elmgren. 2015. Baltic Sea ecosystem-based management under climate change: synthesis and future challenges. AMBIO 44 (S3):507-515. http://dx.doi.org/10.1007/s13280-015-0661-9

Bodin, Ö., and J. Norberg. 2006. A network approach for analyzing spatially structured populations in fragmented landscape. Landscape Ecology 22(1):31-44. http://dx.doi. org/10.1007/s10980-006-9015-0
Bodin, Ö., and C. Prell, editors. 2011. Social networks and natural resource management. Uncovering the social fabric of environmental governance. Cambridge University Pres, Cambridge, UK.

Bodin, Ö., and M. Tengö. 2012. Disentangling intangible socialecological systems. Global Environmental Change 22(2):430-439. http://dx.doi.org/10.1016/j.gloenvcha.2012.01.005

Boonstra, W. J., and J. Hentati-Sundberg. 2014. Classifying fishers' behaviour. An invitation to fishing styles. Fish and Fisheries 17(1):78-100. http://dx.doi.org/10.1111/faf.12092

Casini, M., J. Lövgren, J. Hjelm, M. Cardinale, J.-C. Molinero, and G. Kornilovs. 2008. Multi-level trophic cascades in a heavily exploited open marine ecosystem. Proceedings of the National Academy of Sciences of the United States of America 275 (1644):1793-1801. http://dx.doi.org/10.1098/rspb.2007.1752

Christensen, A.-S., and J. Raakjær. 2006. Fishermen's tactical and strategic decisions. Fisheries Research 81(2-3):258-267. http://dx. doi.org/10.1016/j.fishres.2006.06.018

Cinner, J. E., and Ö. Bodin. 2010. Livelihood diversification in tropical coastal communities: a network-based approach to analyzing 'livelihood landscapes'. PLoS ONE 5(8). http://dx.doi. org/10.1371/journal.pone.0011999

Cline, T. J., D. E. Schindler, and R. Hilborn. 2017. Fisheries portfolio diversification and turnover buffer Alaskan fishing communities from abrupt resource and market changes. Nature Communications 8:14042. http://dx.doi.org/10.1038/ncomms14042

Crona, B. 2006. Supporting and enhancing development of heterogenous ecological knowledge among resource users in a Kenyan seascape. Ecology and Society 11(1):32. [online] URL: http://dx.doi.org/10.5751/ES-01712-110132

Csárdi, G., and T. Nepusz. 2006. The igraph software package for complex network research. Interjournal, Complex Systems 1695. https://pdfs.semanticscholar.org/1d27/44b83519657f5f2610698a8ddd177ced4f5c.pdf

Eggert, H., and R. Tveterås. 2007. Potential rent and overcapacity in the Swedish Baltic Sea trawl fishery for cod (Gadus morhua). ICES Journal of Marine Science 64(3):439-445. http://dx.doi. org/10.1093/icesjms/fsm019

Ellis, F. 2008. The determinants of rural livelihood diversification in developing countries. Journal of Agricultural Economics 51 (2):289-302. http://dx.doi.org/10.1111/j.1477-9552.2000.tb01229. $\underline{\mathrm{X}}$

Essington, T. E., P. E. Moriarty, H. E. Froehlich, E. E. Hodgson, L. E. Koehn, K. L. Oken, M. C. Siple, and C. C. Stawitz. 2015. Fishing amplifies forage fish population collapses. Proceedings of the National Academy of Sciences of the United States of America 112(21):6648-6652. http://dx.doi.org/10.1073/pnas. 1422020112

Feistel, R., G. Nausch, N. Wasmund, C. Hammer, C. von Dorrien, P. Ernst, T. Grohsler, F. Koster, B. MacKenzie, C. Mollmann, G. Wegner, and C. Zimmermann. 2008. Fish stock development under hydrographic and hydrochemical aspects, the history of Baltic Sea fisheries and its management. Pages 543-581 in R. Feistel, G. Nausch, and N. Wasmund, editors. State and evolution 
of the Baltic Sea, 1952-2005: a detailed 50-year survey of meteorology and climate, physics, chemistry, biology, and marine environment. John Wiley \& Sons, Inc., Hoboken, New Jersey, USA. http://dx.doi.org/10.1002/9780470283134

Folke, C. 2016. Resilience. Oxford research encyclopedia of environmental science. Oxford University Press. http://dx.doi. org/10.1093/acrefore/9780199389414.013.8

Folke, C., R. Biggs, A. V. Norström, B. Reyers, and J. Rockström. 2016. Social-ecological resilience and biosphere-based sustainability science. Ecology and Society 21(3):41. http://dx.doi.org/10.5751/ ES-08748-210341

Folke, C., S. R. Carpenter, B. Walker, M. Scheffer, T. Chapin, and J. Rockström. 2010. Resilience thinking: integrating resilience, adaptability and transformability. Ecology and Society 15(4):20. http://dx.doi.org/10.5751/ES-03610-150420

Fuller, E. M., J. F. Samhouri, J. S. Stoll, S. A. Levin, and J. R. Watson. 2017. Characterizing fisheries connectivity in marine social-ecological systems. ICES Journal of Marine Science 74 (8):2087-2096. http://dx.doi.org/10.1093/icesjms/fsx128

Fulton, E. A., A. D. M. Smith, D. C. Smith, and I. E. Van Putten. 2011. Human behaviour: the key source of uncertainty in fisheries management. Fish and Fisheries 12(1):2-17. http://dx.doi. org/10.1111/j.1467-2979.2010.00371.X

Girvan, M., and M. E. J. Newman. 2002. Community structure in social and biological networks. Proceedings of the National Academy of Sciences of the United States of America 99 (12):7821-7826. http://dx.doi.org/10.1073/pnas.122653799

Hentati-Sundberg, J., and J. Hjelm. 2014. Can fisheries management be quantified? Marine Policy 48:18-20. http://dx. doi.org/10.1016/j.marpol.2014.02.021

Hentati-Sundberg, J., J. Hjelm, W. J. Boonstra, and H. Österblom. 2015. Management forcing increased specialization in a fishery system. Ecosystems 18(1):45-61. http://dx.doi.org/10.1007/ s10021-014-9811-3

Hilborn, R., J.-J. Maguire, A. M. Parma, and A. A. Rosenberg. 2001. The Precautionary Approach and risk management: can they increase the probability of successes in fishery management? Canadian Journal of Fisheries and Aquatic Sciences 58(1):99-107. http://dx.doi.org/10.1139/f00-225

Hilborn, R., A. Punt, and J. Orensanz. 2004. Beyond band-aids in fisheries management: fixing world fisheries. Bulletin of Marine Science 74(3):493-507.

International Council for the Exploration of the Sea (ICES). 2017. Report of the Baltic Fisheries Assessment Working Group (WGBFAS). ICES CM 2017/ACOM:11. Copenhagen, Denmark.

International Council for the Exploration of the Sea (ICES) Advisory Committee. 2017. 5.2 Baltic Sea Ecoregion - fisheries overview. ICES Fisheries Overviews: 25.

Kasperski, S., and D. S. Holland. 2013. Income diversification and risk for fishermen. Proceedings of the National Academy of Sciences of the United States of America 110(6):2076-2081. http:// dx.doi.org/10.1073/pnas. 1212278110
Lade, S. J., S. Niiranen, J. Hentati-Sundberg, T. Blenckner, W. J. Boonstra, K. Orach, M. F. Quaas, H. Österblom, and M. Schlüter. 2015. An empirical model of the Baltic Sea reveals the importance of social dynamics for ecological regime shifts. Proceedings of the National Academy of Sciences of the United States of America 112(35):11120-11125. http://dx.doi.org/10.1073/pnas.1504954112

Mackenzie, B. R., H. Gislason, C. Möllmann, and F. W. Köster. 2007. Impact of 21 st century climate change on the Baltic Sea fish community and fisheries. Global Change Biology 13 (7):1348-1367. http://dx.doi.org/10.1111/j.1365-2486.2007.01369. $\underline{\mathrm{X}}$

Mahon, R., P. McConney, and R. N. Roy. 2008. Governing fisheries as complex adaptive systems. Marine Policy 32 (1):104-112. http://dx.doi.org/10.1016/j.marpol.2007.04.011

May, R. M. 1972. Will a large complex system be stable? Nature 238(5364):413-414. http://dx.doi.org/10.1038/238413a0

May, R. M., S. A. Levin, and G. Sugihara. 2008. Complex systems: ecology for bankers. Nature 451(7181):893-895. http://dx.doi. org/10.1038/451893a

Milo, R., S. Shen-Orr, S. Itzkovitz, N. Kashtan, D. Chklovskii, and U. Alon. 2002. Network motifs: simple building blocks of complex networks. Science 298(5594):824-827. http://dx.doi. org/10.1126/science.298.5594.824

Möllmann, C., R. Diekmann, B. Müller-Karulis, G. Kornilovs, M. Plikshs, and P. Axe. 2009. Reorganization of a large marine ecosystem due to atmospheric and anthropogenic pressure: a discontinuous regime shift in the Central Baltic Sea. Global Change Biology 15(6):1377-1393. http://dx.doi.org/10.1111/ j.1365-2486.2008.01814.X

Newman, M. E. J. 2006. Modularity and community structure in networks. Proceedings of the National Academy of Sciences of the United States of America 103(23):8577-8582. http://dx.doi. org/10.1073/pnas.0601602103

Newman, M. E. J., and M. Girvan. 2004. Finding and evaluating community structure in networks. Physical Review E 69 (2):026113. http://dx.doi.org/10.1103/PhysRevE.69.026113

Niiranen, S., J. Yletyinen, M. T. Tomczak, T. Blenckner, O. Hjerne, B. R. Mackenzie, B. Müller-Karulis, T. Neumann, and H. E. M. Meier. 2013. Combined effects of global climate change and regional ecosystem drivers on an exploited marine food web. Global Change Biology 19(11):3327-3342. http://dx.doi. org/10.1111/gcb.12309

Ojaveer, E. 2017. Ecosystems and living resources of the Baltic Sea: their assessment and management. Springer International Publishing. 10.1007/978-3-319-53010-9

Ojaveer, H., A. Jaanus, B. R. Mackenzie, G. Martin, S. Olenin, T. Radziejewska, I. Telesh, M. L. Zettler, and A. Zaiko. 2010. Status of biodiversity in the Baltic Sea. PloS ONE 5(9). http://dx.doi. org/10.1371/journal.pone.0012467

Olsson, J., M. T. Tomczak, H. Ojaveer, A. Gårdmark, A. Põllumäe, B. Müller-Karulis, D. Ustups, G. E. Dinesen, H. Peltonen, I. Putnis, L. Szymanek, M. Simm, O. Heikinheimo, P. Gasyukov, P. Axe, and L. Bergström. 2015. Temporal 
development of coastal ecosystems in the Baltic Sea over the past two decades. ICES Journal of Marine Science 72(9):2539-2548. http://dx.doi.org/10.1093/icesjms/fsv143

Österblom, H., S. Hansson, U. Larsson, O. Hjerne, F. Wulff, R. Elmgren, and C. Folke. 2007. Human-induced trophic cascades and ecological regime shifts in the Baltic Sea. Ecosystems 10:877-889. http://dx.doi.org/10.1007/s10021-007-9069-0

Pauly, D., and M. Palomares. 2005. Fishing down marine food web: It is far more persuasive than we thought. Bulletin of Marine Science 76(2):197-211.

Pelletier, D., and J. Ferraris. 2011. A multivariate approach for defining fishing tactics from commercial catch and effort data. Canadian Journal of Fisheries and Aquatic Sciences 57(1):51-65. http://dx.doi.org/10.1139/f99-176

Perry, R. I., R. E. Ommer, M. Barange, S. Jentoft, B. Neis, and U. R. Sumaila. 2011. Marine social-ecological responses to environmental change and the impacts of globalization. Fish and Fisheries 12:427-450. http://dx.doi.org/10.1111/j.1467-2979.2010.00402. $\underline{\mathrm{X}}$

Pikitch, E. K., C. Santora, E. A. Babcock, A. Bakun, R. Bonfil, D. O. Conover, P. Dayton, P. Doukakis, D. Fluharty, B. Heneman, E. D. Houde, and J. Link. 2004. Ecosystem-based fishery management. Science 305:346-347. http://dx.doi.org/10.1126/ $\underline{\text { science. } 1098222}$

Raakjær Nielsen, J. 2003. An analytical framework for studying: compliance and legitimacy in fisheries management. Marine Policy 27(5):425-432. http://dx.doi.org/10.1016/S0308-597X(03) $\underline{00022-8}$

R Core Team. 2013. R: a language and environment for statistical computing. R Foundation for Statistical Computing, Vienna, Austria. [online] URL http://www.R-project.org/

Robards, M. D., and J. A. Greenberg. 2007. Global constraints on rural fishing communities: whose resilience is it anyway? Fish and Fisheries 8(1):14-30. http://dx.doi.org/10.1111/j.1467-2979.2007.00231. $\underline{\mathrm{X}}$

Rochet, M.-J., and V. M. Trenkel. 2003. Which community indicators can measure the impact of fishing? A review and proposals. Canadian Journal of Fisheries and Aquatic Sciences 60 (1):86-99. http://dx.doi.org/10.1139/f02-164

Salas, S., and D. Gaertner. 2004. The behavioural dynamics of fishers: management implications. Fish Fisheries 5:153-167. http://dx.doi.org/10.1111/j.1467-2979.2004.00146.x

Stirling, A. 2007. A general framework for analysing diversity in science, technology and society. Journal of the Royal Society, Interface 4(15):707-719. http://dx.doi.org/10.1098/rsif.2007.0213

Stouffer, D. B., and J. Bascompte. 2011. Compartmentalization increases food-web persistence. Proceedings of the National Academy of Sciences of the United States of America 108 (9):3648-3652. http://dx.doi.org/10.1073/pnas.1014353108

Travis, J., F. C. Coleman, P. J. Auster, P. M. Cury, J. A. Estes, J. Orensanz, C. H. Peterson, M. E. Power, R. S. Steneck, and J. T. Wootton. 2014. Integrating the invisible fabric of nature into fisheries management. Proceedings of the National Academy of Sciences of the United States of America 111(2):581-584. http:// dx.doi.org/10.1073/pnas.1305853111

Waldo, S., A. Paulrud, and A. Jonsson. 2010. A note on the economics of Swedish Baltic Sea fisheries. Marine Policy 34 (3):716-719. http://dx.doi.org/10.1016/j.marpol.2009.11.007

Wilson, E. O. 2016. Half Earth. Our planet's fight for life. Liveright Publishing Corporation, New York, USA.

Worm, B., E. B. Barbier, N. Beaumont, J. E. Duffy, C. Folke, B. S. Halpern, J. B. C. Jackson, H. K. Lotze, F. Micheli, S. R. Palumbi, E. Sala, K. A. Selkoe, J. J. Stachowicz, and R. Watson. 2006. Impacts of biodiversity loss on ocean ecosystem services. Science 314(5800):787-790. http://dx.doi.org/10.1126/science.1132294

Yletyinen, J., O. Bodin, B. Weigel, M. C. Nordström, E. Bonsdorff, and T. Blenckner. 2016. Regime shifts in marine communities: a complex systems perspective on food web dynamics. Proceedings of the Royal Society B: Biological Sciences 283(1825):20152569. http://dx.doi.org/10.1098/rspb.2015.2569

Zeller, D., P. Rossing, S. Harper, L. Persson, S. Booth, and D. Pauly. 2011. The Baltic Sea: estimates of total fisheries removals 1950-2007. Fisheries Research 108(2-3):356-363. http://dx.doi. org/10.1016/j.fishres.2010.10.024 


\section{APPENDIX 1}

SUPPLEMENTARY MATERIALS TO:

\section{FISHING STRATEGY DIVERSIFICATION AND FISHERS' ECOLOGICAL DEPENDENCY}

\section{SUPPLEMENTARY MATERIALS TABLE OF CONTENTS}

\section{A. Social networks}

- Table S1a. Data for compartmentalization analysis 1996

- Table S1b. Data for compartmentalization analysis 2009

- Table S2a. Data for catches per fishing strategy 1996

- Table S2b. Data for catches per fishing strategy 2009

- Table S3. Sensitivity analysis for compartmentalization

\section{B. Ecological and social-ecological networks}

- Table S4. Ecological network

- Table S5. Sensitivity analysis for social-ecological motifs

- Table S6. Potential changes in the relative fishing pressure

- Figure S1. The relative fishing pressure in 1996 and 2009.

Table A1.1. Data used in the compartmentalization analysis for the number of fishers in primary fishing strategies (FSx), and switching to temporary fishing strategies (sx) in 1996. For example, there are a total of 104 fishers who have FS1 as their primary strategy, and of these, 30 fishers switch to temporary strategy FS2 (s2 in the table). In the social network, links were added if at least $5 \%$ of farmers switched, and the link weights equal to the percentage of fishers that combined their primary strategy with another temporary fishing strategy. Self-loops were removed from the network. FS11 was not practiced as the primary strategy in 1996.

\begin{tabular}{|c|c|c|c|c|c|c|c|c|c|c|c|c|c|}
\hline \multicolumn{14}{|c|}{1996} \\
\hline & s1 & s2 & s3 & s4 & s5 & s6 & s7 & s8 & s9 & s10 & s11 & $\mathrm{s} 12$ & s13 \\
\hline FS1 & 104 & 30 & 9 & 15 & 9 & 17 & 7 & 3 & 3 & 0 & 0 & 0 & 0 \\
\hline FS2 & 19 & 420 & 9 & 6 & 112 & 14 & 30 & 46 & 45 & 8 & 0 & 13 & 0 \\
\hline FS3 & 5 & 4 & 12 & 1 & 2 & 5 & 1 & 1 & 0 & 0 & 0 & 0 & 0 \\
\hline FS4 & 8 & 3 & 4 & 20 & 1 & 6 & 1 & 0 & 0 & 0 & 0 & 0 & 0 \\
\hline FS5 & 4 & 69 & 3 & 2 & 118 & 7 & 5 & 13 & 13 & 4 & 0 & 2 & 0 \\
\hline
\end{tabular}




\begin{tabular}{|l|r|r|r|r|r|r|r|r|r|r|r|r|r|}
\hline FS6 & 5 & 2 & 2 & 4 & 0 & 10 & 0 & 2 & 0 & 0 & 0 & 0 & 0 \\
\hline FS7 & 1 & 6 & 0 & 1 & 5 & 1 & 17 & 0 & 1 & 0 & 0 & 1 & 0 \\
\hline FS8 & 0 & 9 & 1 & 0 & 2 & 1 & 1 & 16 & 4 & 0 & 0 & 1 & 0 \\
\hline FS9 & 0 & 9 & 0 & 0 & 7 & 0 & 8 & 4 & 21 & 0 & 1 & 0 & 0 \\
\hline FS10 & 0 & 4 & 0 & 0 & 8 & 0 & 0 & 0 & 4 & 38 & 5 & 12 & 8 \\
\hline FS11 & & & & & & & & & & & & & \\
\hline FS12 & 0 & 8 & 0 & 0 & 15 & 0 & 2 & 1 & 1 & 22 & 3 & 113 & 6 \\
\hline FS13 & 0 & 0 & 0 & 0 & 0 & 0 & 0 & 0 & 0 & 18 & 4 & 6 & 23 \\
\hline
\end{tabular}

Table A1.2. Data used in the compartmentalization analysis for number of fishers in primary fishing strategies (FSx) and switching to temporary fishing strategies (sx) in 2009. Self-loops were removed. See Table S1a caption for how the data was used in network construction.

\begin{tabular}{|c|c|c|c|c|c|c|c|c|c|c|c|c|c|}
\hline \multicolumn{14}{|l|}{2009} \\
\hline & s1 & s2 & s3 & s4 & s5 & s6 & s7 & s8 & s9 & s10 & s11 & $\mathrm{s} 12$ & s13 \\
\hline FS1 & 37 & 9 & 0 & 6 & 5 & 3 & 0 & 1 & 0 & 0 & 0 & 0 & 0 \\
\hline FS2 & 6 & 168 & 5 & 5 & 71 & 6 & 47 & 28 & 0 & 9 & 0 & 1 & 0 \\
\hline FS3 & 3 & 6 & 13 & 6 & 6 & 3 & 3 & 2 & 0 & 0 & 0 & 0 & 0 \\
\hline FS4 & 8 & 6 & 4 & 16 & 3 & 2 & 1 & 2 & 0 & 0 & 0 & 0 & 0 \\
\hline FS5 & 3 & 16 & 3 & 2 & 41 & 1 & 1 & 9 & 0 & 2 & 0 & 2 & 0 \\
\hline FS6 & 4 & 7 & 3 & 3 & 2 & 9 & 1 & 0 & 0 & 0 & 0 & 0 & 0 \\
\hline FS7 & 0 & 25 & 1 & 1 & 9 & 0 & 38 & 4 & 1 & 1 & 0 & 1 & 0 \\
\hline FS8 & 0 & 7 & 1 & 0 & 5 & 0 & 1 & 7 & 0 & 0 & 0 & 0 & 0 \\
\hline FS9 & 1 & 1 & 0 & 0 & 1 & 0 & 1 & 0 & 2 & 0 & 0 & 0 & 0 \\
\hline FS10 & 0 & 1 & 0 & 0 & 0 & 0 & 1 & 0 & 0 & 11 & 4 & 5 & 5 \\
\hline FS11 & 0 & 0 & 0 & 0 & 0 & 0 & 0 & 0 & 0 & 8 & 13 & 6 & 1 \\
\hline FS12 & 0 & 1 & 0 & 0 & 12 & 0 & 1 & 0 & 0 & 1 & 1 & 55 & 0 \\
\hline s13 & 0 & 0 & 0 & 0 & 0 & 0 & 0 & 0 & 0 & 4 & 5 & 0 & 22 \\
\hline
\end{tabular}


Table A2.1. Data for fishing links as catch (kilograms) per fishing event (trip) per an average fisher in each strategy in 1996. In the social-ecological network construction, a link was added from a fishing strategy to a target fish species if the average catch for a species exceeded $2 \%$ of the average total catch for that particular fishing strategy. The following abbreviations are used: FS: fishing strategy, CO: cod, HE: herring, SP: sprat; SA: salmon, FL: flounder, PL: plaice, NP: Northern pike, PP: Pikeperch, PE: perch, TU: turbot, EE: eel, WH: whitefish, TR: seatrout.

\begin{tabular}{|l|r|r|r|r|r|r|r|r|r|r|r|r|r|}
\hline \multicolumn{10}{|l|}{1996} & CI \\
\hline & CO & HE & SP & SA & FL & PL & NP & PP & PE & TU & EE & WH & TR \\
\hline FS1 & 1152 & 11 & 0 & 1091 & 1 & 0 & 27 & 0 & 7 & 0 & 25 & 3 & 178 \\
\hline FS2 & 1652 & 2 & 0 & 0 & 6 & 0 & 3 & 0 & 1 & 4 & 0 & 2 & 1 \\
\hline FS3 & 4584 & 105 & 228 & 0 & 162 & 15 & 0 & 0 & 0 & 10 & 1 & 0 & 0 \\
\hline FS4 & 85 & 244 & 0 & 3 & 92 & 1 & 99 & 6 & 64 & 11 & 917 & 44 & 5 \\
\hline FS5 & 1373 & 5 & 0 & 1 & 38 & 1 & 1 & 1 & 3 & 3 & 1 & 2 & 1 \\
\hline FS6 & 15 & 2 & 0 & 1 & 11 & 1 & 196 & 744 & 209 & 2 & 10 & 387 & 16 \\
\hline FS7 & 2 & 0 & 0 & 0 & 20 & 0 & 100 & 33 & 410 & 1 & 10 & 35 & 3 \\
\hline FS8 & 1374 & 2241 & 0 & 0 & 10 & 0 & 4 & 6 & 8 & 2 & 6 & 0 & 0 \\
\hline FS9 & 119 & 17796 & 1608 & 0 & 0 & 0 & 0 & 0 & 2 & 0 & 1 & 1 & 0 \\
\hline FS10 & 19 & 117245 & 179261 & 0 & 0 & 0 & 0 & 0 & 0 & 0 & 0 & 0 & 0 \\
\hline FS11 & 20 & 2226 & 15866 & 1 & 0 & 0 & 0 & 0 & 0 & 0 & 1 & 0 & 0 \\
\hline FS12 & 17 & 1 & 0 & 766 & 0 & 0 & 0 & 0 & 0 & 3 & 0 & 1 & 121 \\
\hline FS13 & 21 & 0 & 0 & 0 & 5 & 1 & 1 & 1 & 0 & 448 & 0 & 0 & 3 \\
\hline
\end{tabular}

Table A2.2. Data for fishing links as catch (kilograms) per fishing event (trip) per an average fisher in each strategy in 2009 See Table S2a caption for how the data was used in network construction. The following abbreviations are used: FS: fishing strategy, CO: cod, HE: herring, SP: sprat; SA: salmon, FL: flounder, PL: plaice, PI: Northern pike, PP: Pikeperch, PE: perch, TU: turbot, WH: whitefish, TR: seatrout.

\begin{tabular}{|l|l|l|l|l|l|l|l|l|l|l|l|l|l|}
\hline \multicolumn{2}{|l|}{2009} & SP \\
\hline & CO & HE & SP & SA & FL & PL & NP & PP & PE & TU & EE & WH & TR \\
\hline
\end{tabular}




\begin{tabular}{|c|r|r|r|r|r|r|r|r|r|r|r|r|r|}
\hline FS1 & 626 & 0 & 0 & 62 & 0 & 0 & 0 & 0 & 0 & 0 & 1 & 0 & 2 \\
\hline FS2 & 588 & 1 & 0 & 0 & 7 & 7 & 1 & 0 & 0 & 1 & 0 & 2 & 0 \\
\hline FS3 & 4670 & 144 & 60 & 0 & 24 & 45 & 0 & 0 & 0 & 4 & 0 & 0 & 0 \\
\hline FS4 & 139 & 20 & 0 & 4 & 33 & 0 & 13 & 6 & 8 & 3 & 196 & 35 & 20 \\
\hline FS5 & 317 & 0 & 0 & 0 & 56 & 13 & 0 & 0 & 1 & 2 & 0 & 1 & 1 \\
\hline FS6 & 21 & 0 & 0 & 1 & 9 & 0 & 136 & 187 & 100 & 0 & 3 & 192 & 2 \\
\hline FS7 & 0 & 1 & 0 & 0 & 37 & 0 & 16 & 2 & 254 & 0 & 0 & 31 & 1 \\
\hline FS8 & 695 & 3024 & 0 & 0 & 43 & 4 & 9 & 0 & 8 & 5 & 0 & 2 & 0 \\
\hline FS9 & 108 & 14608 & 1880 & 3 & 0 & 0 & 1 & 0 & 0 & 0 & 0 & 0 & 0 \\
\hline FS10 & 169 & 95804 & 171413 & 1 & 0 & 0 & 0 & 0 & 0 & 0 & 0 & 0 & 0 \\
\hline FS11 & 29 & 5041 & 9225 & 0 & 0 & 0 & 0 & 0 & 0 & 0 & 0 & 0 & 0 \\
\hline FS12 & 57 & 0 & 0 & 1483 & 0 & 0 & 1 & 0 & 0 & 0 & 0 & 0 & 15 \\
\hline FS13 & 13 & 0 & 0 & 0 & 1 & 1 & 0 & 0 & 0 & 91 & 0 & 0 & 0 \\
\hline
\end{tabular}

Table A3. Ecological network used in the social-ecological analysis. Predator species are placed in rows and prey species in columns.

\begin{tabular}{|c|c|c|c|c|c|c|c|c|c|c|c|c|}
\hline & 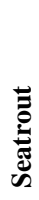 & $\frac{\ddot{8}}{\grave{E}}$ & 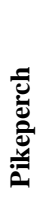 & 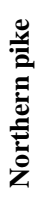 & تُّ & 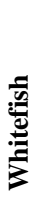 & ల] & ن & $\frac{\vec{J}}{\vec{L}}$ & 苞 & 哭 & 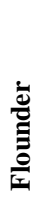 \\
\hline \multicolumn{13}{|l|}{ Seatrout } \\
\hline \multicolumn{13}{|l|}{ Turbot } \\
\hline Pikeperch & 1 & & & 1 & 1 & 1 & & & 1 & 1 & 1 & 1 \\
\hline Northern pike & 1 & 1 & 1 & 1 & & 1 & & & 1 & 1 & 1 & 1 \\
\hline Perch & 1 & & 1 & 1 & 1 & 1 & & & 1 & 1 & 1 & 1 \\
\hline \multicolumn{13}{|l|}{ Whitefish } \\
\hline \multicolumn{13}{|l|}{ Eel } \\
\hline Cod & & 1 & & & 1 & & & 1 & 1 & 1 & & 1 \\
\hline \multicolumn{13}{|l|}{ Sprat } \\
\hline Herring & & & & & & & & & & 1 & & \\
\hline Salmon & & & & & & & & & 1 & 1 & & \\
\hline Flounder & & & & & & & & & & & & \\
\hline
\end{tabular}


Table A4. Compartmentalization sensitivity analysis for link thresholds $(\mathrm{TH}) 2 \%, 5 \%$ and $10 \%$ in compartmentalization analysis. In the sensitivity analysis, links below each threshold were removed from the social networks, and the table presents compartmentalization results for the resulting $2 \%, 5 \%$ and $10 \%$ threshold networks. The table presents the number of compartments $(\mathrm{N})$ for each network, and fishing strategy (FS) memberships in each compartment.

\begin{tabular}{|c|c|c|c|c|c|}
\hline Network & $\mathbf{N}$ & Compartment 1 & Compartment 2 & Compartment 3 & Compartment 4 \\
\hline $\begin{array}{l}1996 \\
\text { TH2 }\end{array}$ & 3 & $\begin{array}{l}\text { FS1, FS3, FS4, } \\
\text { FS6 }\end{array}$ & $\begin{array}{l}\text { FS2, FS5, FS7, } \\
\text { FS8, FS9 }\end{array}$ & $\begin{array}{l}\text { FS10, FS11, FS12, } \\
\text { FS13 }\end{array}$ & \\
\hline $\begin{array}{l}1996 \\
\text { TH5 }\end{array}$ & 3 & $\begin{array}{l}\text { FS1, FS3, FS4, } \\
\text { FS6 }\end{array}$ & $\begin{array}{l}\text { FS2, FS5, FS7, } \\
\text { FS8, FS9 }\end{array}$ & $\begin{array}{l}\text { FS10, FS11, FS12, } \\
\text { FS13 }\end{array}$ & \\
\hline $\begin{array}{l}1996 \\
\text { TS10 }\end{array}$ & 4 & $\begin{array}{l}\text { FS1, FS3, FS4, } \\
\text { FS6 }\end{array}$ & FS2, FS8, FS9 & FS7 & $\begin{array}{c}\text { FS5, FS10, FS11, } \\
\text { FS12, FS13 }\end{array}$ \\
\hline 2009 TS2 & 2 & $\begin{array}{l}\text { FS1, FS2, FS3, } \\
\text { FS4, FS5, FS6, } \\
\text { FS7, FS8, FS9 }\end{array}$ & $\begin{array}{l}\text { FS10, FS11, FS12, } \\
\text { FS13 }\end{array}$ & & \\
\hline 2009 TS5 & 2 & $\begin{array}{l}\text { FS1, FS2, FS3, } \\
\text { FS4, FS5, FS6, } \\
\text { FS7, FS8, FS9 }\end{array}$ & $\begin{array}{l}\text { FS10, FS11, FS12, } \\
\text { FS13 }\end{array}$ & & \\
\hline $\begin{array}{l}2009 \\
\text { TS10 }\end{array}$ & 2 & $\begin{array}{l}\text { FS1, FS2, FS3, } \\
\text { FS4, FS5, FS6, } \\
\text { FS7, FS8, FS9 }\end{array}$ & $\begin{array}{l}\text { FS10, FS11, FS12, } \\
\text { FS13 }\end{array}$ & & \\
\hline
\end{tabular}

\section{Table A5. Motif sensitivity analysis}

Motif sensitivity analysis for link thresholds (TH) $2 \%, 5 \%$ and $10 \%$. In the sensitivity analysis, links below each threshold were removed from the social-ecological networks, and the table presents motif results for the resulting $2 \%, 5 \%$ and $10 \%$ threshold networks.

\begin{tabular}{|c|c|c|c|c|}
\hline Motif & Empirical & $\begin{array}{l}\text { Random count } \\
\text { (mean) }\end{array}$ & $\begin{array}{l}\text { Standard } \\
\text { deviation }\end{array}$ & T-ratio \\
\hline \multicolumn{5}{|c|}{1996 Threshold 5\% } \\
\hline T1 & 8 & 3.770000 & 1.716556 & $2.464236 *$ \\
\hline T2 & 1 & 3.070000 & 1.615925 & 1.281000 \\
\hline T3 & 73 & 82.980000 & 6.628649 & 1.505586 \\
\hline S1 & 13 & 15.330000 & 5.745538 & 0.405532 \\
\hline S2 & 29 & 13.530000 & 4.361111 & $3.547261 * *(+)$ \\
\hline $\mathbf{S 3}$ & 16 & 19.640000 & 5.584104 & $0.651850 "$ \\
\hline \multicolumn{5}{|c|}{1996 Threshold $10 \%$} \\
\hline T1 & 6 & 2.040000 & 1.549976 & $2.554879 *(+)$ \\
\hline T2 & 2 & 3.020000 & 1.537281 & 0.663509 \\
\hline T3 & 48 & 51.080000 & 4.730473 & 0.651098 \\
\hline S1 & 7 & 8.290000 & 3.266899 & 0.394870 \\
\hline S2 & 25 & 13.370000 & 4.210749 & $2.761979 *(+)$ \\
\hline S3 & 9 & 10.780000 & 3.249180 & 0.547831 \\
\hline \multicolumn{5}{|c|}{2009 Threshold 5\% } \\
\hline T1 & 1 & 1.300000 & 0.948151 & 0.316405 \\
\hline
\end{tabular}




\begin{tabular}{|l|l|l|l|l|}
\hline T2 & 1 & 1.350000 & 0.967920 & 0.361600 \\
\hline T3 & 39 & 49.200000 & 4.447221 & $2.293567 *(-)$ \\
\hline S1 & 2 & 6.860000 & 2.916411 & 1.666432 \\
\hline S2 & 3 & 6.790000 & 2.879026 & $2.156980 *(+)$ \\
\hline S3 & 16 & 6.960000 & 2.673930 & 0.359022 \\
\hline 2009 Threshold 5\% \% & 1 & 0.960000 & 0.952615 & 0.041990 \\
\hline T1 & 1 & 1.160000 & 1.143449 & 1.014475 \\
\hline T2 & 0 & 40.010000 & 3.988608 & $2.258934^{*}(-)$ \\
\hline T3 & 31 & 4.520000 & 2.226924 & $2.029705^{*}(-)$ \\
\hline S1 & 0 & 6.130000 & 2.852095 & $2.408756^{*}(+)$ \\
\hline S2 & 13 & 4.920000 & 2.588553 & 0.355411 \\
\hline S3 & 4 & & & \\
\hline
\end{tabular}

Table A6. Potential changes in the relative pressure on fish species as change between the years 1996 and 2009 in percentage points. The numbers are calculated for an average fisher per fishing strategy. Green colour is used to mark the increase in fishing pressure from 1996 to 2009, and yellow marks decrease. This table is based on the data same data as Tables S1a and S1b. The table aids to comprehend differences in Figure S1 link weights.

\begin{tabular}{|c|c|c|c|c|c|c|c|c|c|c|c|c|c|}
\hline & $\mathrm{CO}$ & $\mathrm{HE}$ & SP & SA & $\mathrm{FL}$ & PL & NP & PP & $\mathrm{PE}$ & TU & $\mathrm{EE}$ & WH & TR \\
\hline FS1 & 44 & 0 & 0 & -35 & 0 & 0 & -1 & 0 & 0 & 0 & -1 & 0 & -7 \\
\hline FS2 & -2 & 0 & 0 & 0 & 1 & 1 & 0 & 0 & 0 & 0 & 0 & 0 & 0 \\
\hline FS3 & 5 & 1 & -3 & 0 & -3 & 1 & 0 & 0 & 0 & 0 & 0 & 0 & 0 \\
\hline FS4 & 24 & -11 & 0 & 1 & 1 & 0 & -4 & 1 & -2 & 0 & -17 & 5 & 4 \\
\hline FS5 & -15 & 0 & 0 & 0 & 12 & 3 & 0 & 0 & 0 & 0 & 0 & 0 & 0 \\
\hline FS6 & 2 & 0 & 0 & 0 & 1 & 0 & 9 & -18 & 2 & 0 & 0 & 5 & -1 \\
\hline FS7 & 0 & 0 & 0 & 0 & 8 & 0 & -12 & -5 & 7 & 0 & -2 & 3 & 0 \\
\hline FS8 & -19 & 18 & 0 & 0 & 1 & 0 & 0 & 0 & 0 & 0 & 0 & 0 & 0 \\
\hline FS9 & 0 & -3 & 3 & 0 & 0 & 0 & 0 & 0 & 0 & 0 & 0 & 0 & 0 \\
\hline FS10 & 0 & -4 & 4 & 0 & 0 & 0 & 0 & 0 & 0 & 0 & 0 & 0 & 0 \\
\hline FS11 & 0 & 23 & -23 & 0 & 0 & 0 & 0 & 0 & 0 & 0 & 0 & 0 & 0 \\
\hline FS12 & 2 & 0 & 0 & 11 & 0 & 0 & 0 & 0 & 0 & 0 & 0 & 0 & -12 \\
\hline FS13 & 8 & 0 & 0 & 0 & 0 & 1 & 0 & 0 & 0 & -7 & 0 & 0 & -1 \\
\hline
\end{tabular}


1996

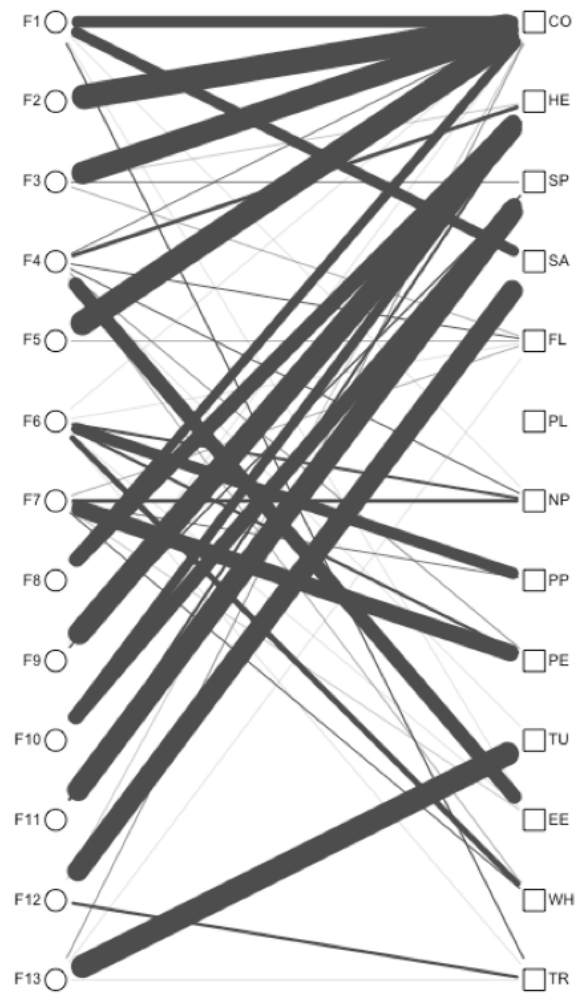

2009

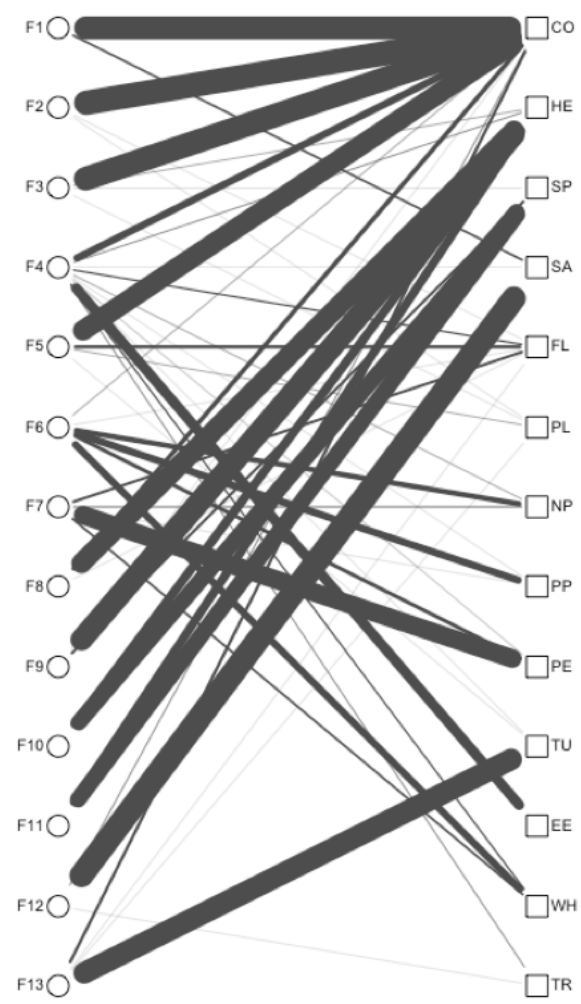

Figure A1. The relative fishing pressure on fish species. The width of the links from each fishing strategy (Fx) indicate the percentage of catch per species for an average fisher in that strategy (raw data presented in Tables S1a and S1b). The following abbreviations are used: FS: fishing strategy, CO: cod, HE: herring, SP: sprat; SA: salmon, FL: flounder, PL: plaice, NP: Northern pike, PP: Pikeperch, PE: perch, TU: turbot, EE: eel, WH: whitefish, TR: seatrout. 